\title{
The essential oil of Lippia alba Mill (Lamiales:Verbenaceae) as mosquitocidal and repellent agent against Culex quinquefasciatus Say (Diptera: Culicidae) and Aedes aegypti Linn (Diptera: Culicidae)
}

Sudarshana Mahanta, Riju Sarma and Bulbuli Khanikor ${ }^{*}$

\begin{abstract}
Background: Being a low-risk insecticide, plant essential oils emerge as competent mosquitocidal and repellent candidates. However, essential oil may act differently in different mosquito species and different developmental stages of same mosquito species. In the current investigation, we evaluated the ovicidal, larvicidal, adulticidal and repellent activities of essential oil extracted from the leaves of Lippia alba against two medically important mosquito species, Aedes aegypti and Culex quinquefasciatus. The efficacy of the oil was assessed under laboratory conditions against different developmental stages of the selected species.

Results: From the findings, it can be inferred that $L$. alba oil is more effective as a repellent against both the targeted mosquito species. Results also demonstrated that ovicidal, larvicidal and repellent properties of the essential oil were higher against Culex quinquefasciatus than Aedes aegypti. GC-MS analysis of the oil showed the presence of aromadendrene oxide, caryophyllene oxide, etc. as major constituent compounds.

Conclusion: The outcomes of this study clearly indicated that the essential oil of L. alba has the potentiality to act more effectively as a repellent, followed by a larvicidal agent against mosquito and at the same time the results revealed differential vulnerability of different mosquito species and their life stages against a particular plant essential oil.
\end{abstract}

Keywords: Lippia alba, Essential oil, Aedes aegypti, Culex quinquefasciatus

\section{Background}

Repeated use of synthetic insecticides for controlling mosquitoes has created severe trouble like resurgences of mosquitoes and undesirable effects on non-target organisms. It has also fostered environmental and human health concerns and led to the development of resistance in mosquito populations. Therefore, it is needful to generate some novel insecticides which have low mammalian toxicity, eco-friendliness and at the same time effective in killing mosquitoes or to prevent biting of mosquitoes. A number of natural products in the form of plant extracts, plant essential oils and compounds having insecticidal

\footnotetext{
* Correspondence: khanikorbulbuli@yahoo.co.in

Department of Zoology, Gauhati University, Guwahati, Assam 781014, India
}

value have been extensively studied in different countries across the world against diverse pests including mosquitoes. Researchers are also observing the combined efficacy of the plant-based product and bacteria-based insecticide with chemical insecticides to increase the effectiveness of a vector control strategy (Nassar and El-Sebaii, 1999; Nassar, Ghramh, Al-Wazi, Mahyoub, Ahmed, 2017). However, detail studies on some of the commonly found aromatic plants are still lacking which can be effective against mosquito vectors.

Lippia is one of the important genera of the family Verbenaceae which comprises around 220 species (Ngassapa, Runtoro, Harvala, and Chinou, 2003). Among these, Lippia alba (Verbenaceae) is an aromatic, perennial shrub, 
found in different countries including India. In Assam, the plant is widely grown and locally known as "pikhachi bon". Traditionally the plant is used as spice among different tribes in the state. Some of the researchers have explored several major compounds from $L$. alba essential oils which were found to possess anti-viral, anti-bacterial, anti-fungal activities (Rahmatillah et al. 2011). The efficacy of essential oil from leaves of $L$. alba has not been studied widely against mosquitoes, although the repellent activity was established against $A$. aegypti (Castillo, Stashenko, and Duque, 2017). Besides this, the repellent property of the plant was also reported against stored grain pests (Peixoto et al. 2015). Keeping it on the mind, a detailed study on the efficacy of $L$. alba (leaves) oil was done against all the developmental stages of $C$. quinquefasciatus and $A$. aegypti which is not found to be reported yet.

In addition, vector control measures will be successful if we are able to identify the selective toxicity of a plant essential oil towards different mosquito species as well as their different developmental stages. This is because a variety of mosquito species with their different developmental stages may be present together in a particular location where mosquitocides are applied and or dominance of a particular mosquito species may be higher in a particular geographical locality. Insufficiency in the knowledge of the toxicity of controlling agent and its species specificity, the control measures would not give expected results. The same essential oil may not have a similar activity towards different mosquito species. Even it does not affect equally against different developmental stages of a single species. To broaden the information of the mosquitocidal activity of $L$. alba oil, an attempt was made in the current investigation to access its efficacy against different developmental stages of Aedes aegypti and Culex quinquefasciatus.

\section{Materials and methods}

Rearing of $A$. aegypti and C. quinquefasciatus

The eggs of $A$. aegypti and C. quinquefasciatus were collected from Regional Medical Research Laboratory (RMRC), Dibrugarh, Assam, India. The collected eggs were reared in the insect culture room, Department of Zoology, Gauhati University, Assam, India, by following the rearing practices described by Arivoli and Tennyson (2011). The colonies were maintained at the temperature between 25 and $29{ }^{\circ} \mathrm{C}$ temperature and $80-90 \%$ relative humidity. Larvae were fed on larval food (powdered dog biscuit and yeast in the ratio 3:1) and adult mosquitoes were fed on $10 \%$ glucose solution. Pupae were transferred to a disposable cup and it was kept inside the cage. On the fifth day after hatching, adult female mosquitoes were blood-fed on albino rats.

\section{Collection of plant material}

Leaves of Lippia alba were collected from Jalukbari, Guwahati, Assam, India. Plant materials were collected in the period of March to June 2018. Collected specimens were identified in the Department of Botany, Gauhati University, Assam, India.

\section{Essential oil extraction}

Fresh plant materials were taken for the extraction of essential oil and no solvent was used in it. The essential oil was extracted from fresh the plant materials with the help of Clevenger apparatus by the hydro-distillation method described by Kumar, Kumar, Prasal, Dubey, and Samant (2008) with little modification. Five hundred grams of plant material was taken for the extraction. The apparatus was run for $6 \mathrm{~h}$ after boiling of water. The extracted essential oil was collected in glass vials, few crystals of anhydrous sodium sulphate were added to absorb excess water present in collected plant oil and the vial was stored in $4^{\circ}$ centigrade.

\section{Activity of essential oils Ovicidal activity}

The ovicidal bioassay was performed according to the method described by Tennyson, Ravindran, and Arivoli (2011) and Pushpanathan, Jebanesan, and Govindarajan (2006) with little modifications. Initially, two concentrations (1000 ppm and $500 \mathrm{ppm}$ ) were used to observe its effect and based on the findings; six different concentrations $(1000 \mathrm{ppm}, 500 \mathrm{ppm}, 250 \mathrm{ppm}, 100 \mathrm{ppm}, 50 \mathrm{ppm}$, $10 \mathrm{ppm}$ ) were applied to determine the sublethal concentration (LC50). Fifty eggs of each of the mosquito species were exposed to each concentration of essential oil. Dimethyl sulfoxide (DMSO) was used as an emulsifying agent for the preparation of each concentration. Each experiment was replicated thrice along with appropriate control (DMSO-treated water as positive control and water as the negative control).

$$
\begin{aligned}
& \text { Percent ovicidal activity } \\
& =\left(\% \text { of eggs hatched in control }-\begin{array}{r}
\% \text { eggs hatched in treated } / \% \\
\text { of eggs hatched in control }
\end{array}\right) \times 100
\end{aligned}
$$

\section{Larvicidal bioassay}

The efficacy of essential oil of $L$. alba was studied by performing bioassay against third instar larval stages of A. aegypti and C. quinquefasciatus. The larvicidal activity of the essential oil was assayed following the method described by Tong and Bloomquist (2013). For larvicidal bioassay, batches of 20 numbers of healthy larvae were transferred to the disposable cups (depth $10 \mathrm{~cm}$ ) containing $100 \mathrm{ml}$ of water. At first, two concentrations (1000 ppm and $500 \mathrm{ppm})$ were used to observe its 
efficacy after which six different concentrations (1000 ppm, 500 ppm, 250 ppm, 100 ppm, 50 ppm, 10 ppm) were applied. Test solutions were prepared by mixing an equal amount of essential oil and dimethyl sulfoxide (DMSO) which acts as an emulsifier. The LC50 concentration was calculated after $24 \mathrm{~h}, 48 \mathrm{~h}$, and $72 \mathrm{~h}$ of exposure. Each concentration was set in triplicate along with one control group in water and one in DMSO. If the pupation occurred during the exposure period and more than 10\%larvae died in the control group then the test was repeated. The mortality in the control groups if occurred between 5 and $10 \%$, then the mortality of the treated group was calculated by using Abbott's formula:

$$
\text { Mortality }(\%)=[(x-y) / x] \cdot 100
$$

Where $x=$ percentage survival in the control group and $y=$ percentage survival in the treated group. Data from all replicates were pooled for analysis.

\section{Adulticidal bioassay}

For the adulticidal bioassay, the impregnated filter paper bioassay method described by Ramar, Ignacimuthu, and Paulraj (2013) was followed with some modifications. For this assay, 10 numbers of 4-5 days old non-bloodfed female mosquitoes were selected for each concentration. Three replicates were made for each concentration. Based on the preliminary screening at $1000 \mathrm{ppm}$ and $500 \mathrm{ppm}$ of concentrations, six different concentrations (1000 ppm, 500 ppm, 250 ppm, 100 ppm, 50 ppm, 10 $\mathrm{ppm}$ ) of selected essential oil were prepared in $2 \mathrm{ml}$ of acetone and applied on Whatman no.1 filter papers (size $12 \times 15 \mathrm{~cm}^{2}$ ). Control papers were treated with $2 \mathrm{ml}$ of acetone alone and placed in exposure tubes. 3-5-day-old sugar-fed mosquitoes are transferred to each tube after the evaporation time of $10 \mathrm{~min}$ of acetone. The LC50 dose was recorded after the values were pooled for analysis in the log dose probit analysis. If mortality exceeded $20 \%$ in the control batch, the whole test was rejected and repeated. Acetone was used as a positive control.

\section{Repellent bioassay}

The repellency of the essential oil was evaluated using the human-bait technique Pushpanathan, Jebanesan, and Govindaranjan (2008). The test was carried out in a net cage $(45 \times 30 \times 25 \mathrm{~cm} 2)$ containing 100 blood starved female $C$. quinquefasciatus of $3-4$ days old at $28 \pm 2{ }^{\circ} \mathrm{C}$ and relative humidity of $65-80 \%$. The volunteer had no contact with any other chemicals on the day of the assay. Only $25 \mathrm{~cm}^{2}$ dorsal side of the skin on each arm of the volunteer was exposed and the remaining area covered by rubber gloves. The essential oil of $L$. alba was applied at $1.0 \mathrm{mg} / \mathrm{cm}^{2}$ separately in the exposed area of the forearm. Ethanol was served as control. Each bioassay was performed between 17:00 and 20:00 h for C. quinquefasciatus and for A. aegypti it was tested between 9:00 and 12:00 h. The control and treated arms were introduced together into the mosquito cage. Each test concentration was repeated three times. The volunteer conducted their test of each concentration by putting the treated and control arm into the same cage for one full minute for every $5 \mathrm{~min}$. The mosquitoes that landed on the hand were recorded and then shaken off to avoid imbibing of blood; making out 5-min protection. The percentage of repellency was calculated by the following formula

$$
\% \text { Repellency }=(T a-T b / T a) 100
$$

where $\mathrm{Ta}$ is the number in the control group and $\mathrm{Tb}$ is the number of mosquitoes in the treated group.

Sublethal repellent time (RT50) of the selected essential oil, i.e., the time at which $50 \%$ of mosquito was repelled was also calculated for a single dose of $1 \mathrm{mg} / \mathrm{cm}^{2}$ for both of the target species.

\section{Analysis of effective essential oil components}

The GC-MS analysis was carried out to identify the constituents of the essential oil extracted from the fresh leaves of L. alba (Fig. 1). Sample of the essential oil was analysed using gas chromatography-mass spectrometry. GC analysis was carried out on an Agilent GC 7890 A and mass spectrophotometry in Accu TOF GCv from Jeol instrument. Gas chromatograph equipped with an FID detector and a capillary column (HP5-MS). The carrier gas was helium at a flow rate of $1 \mathrm{ml} / \mathrm{min}$. The splitting program was set as $2 \mathrm{M}-10-200-3 \mathrm{M}-10-270-5 \mathrm{M}$ 10-280-1 M-HP5. The identity, retention time, area and percentage composition of the constituent compounds present in the essential oil extracted from the leaves of $L$ .alba is presented in the Table 5 .

\section{Statistical analysis}

The LC50 and RT50 values were calculated by probit analysis using SPSS (version 16) and MINITAB software.

\section{Result}

The essential oil extracted from fresh leaves of Lippia alba possesses light yellow colour and strong odours. In the present study, an average $0.003 \%$ of essential oil was extracted from the leaves of the same.

\section{Ovicidal activity}

During the study of the ovicidal activity of the essential oil against both the target mosquitoes, hatching of larvae were recorded from $24 \mathrm{~h}$ to $72 \mathrm{~h}$ as in the control, the hatching was observed up to $72 \mathrm{~h}$ (Table 3). Results of 


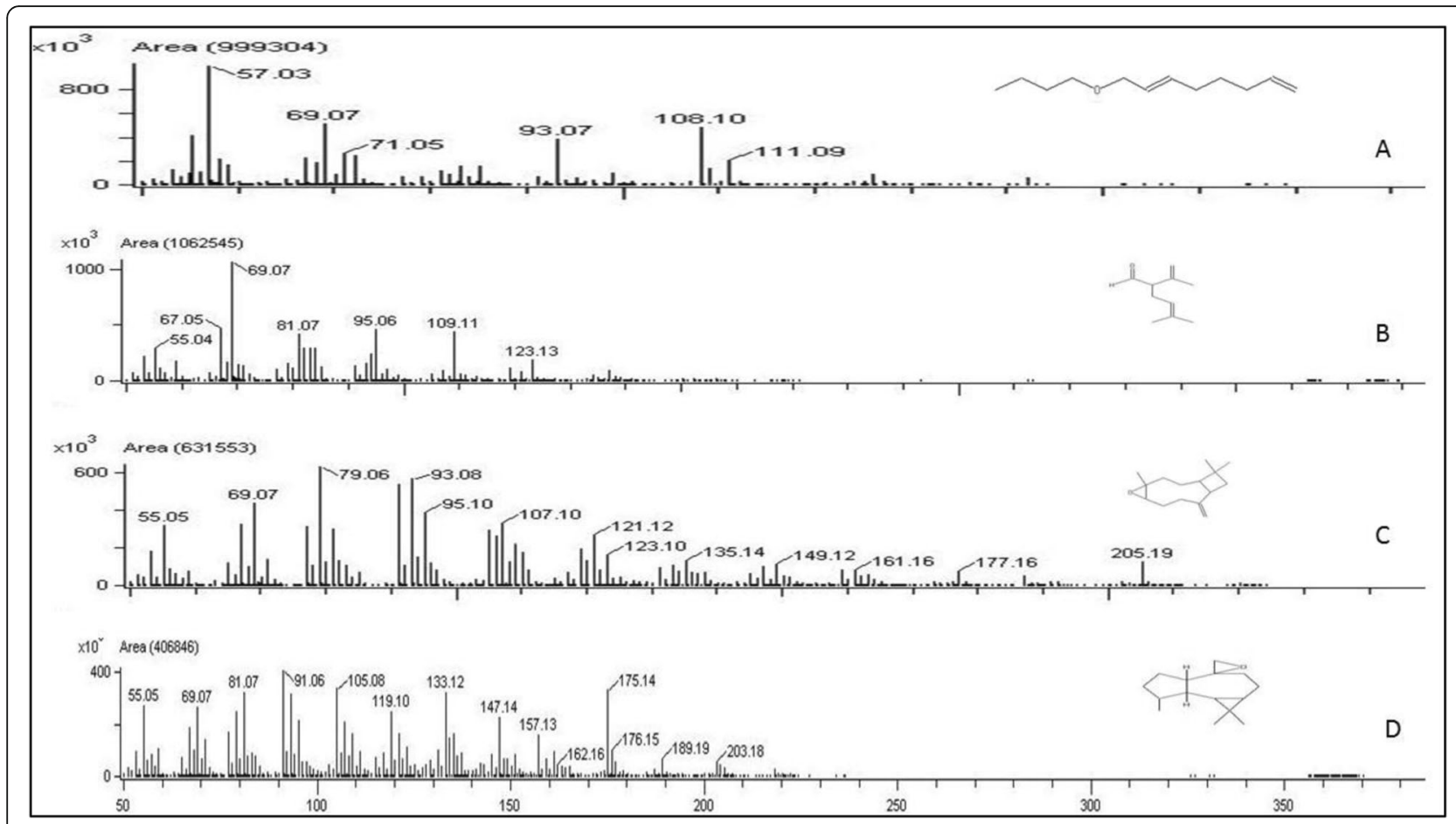

Fig. 1 MS of major constituent compounds of L. alba oil. a 2,7 octadione-1-butoxy. b 2-isopropenyl-5-methyl hex-4-enol. c Caryophyllene oxide. d Aromdendrene oxide

the pilot study demonstrated that at $1000 \mathrm{ppm}$ concentration, $9.7 \%, 32.2 \%$ and $43.6 \%$ hatching of C. quinquefasciatus were recorded while at $500 \mathrm{ppm}$ concentration, $15.4 \%, 42.3 \%$ and $59.9 \%$ hatching were recorded after 24 $\mathrm{h}, 48 \mathrm{~h}$ and $72 \mathrm{~h}$, respectively. For $A$. aegypti, hatching percentage at $1000 \mathrm{ppm}$ concentration was recorded as $11.9 \%, 45.9 \%, 50.4 \%$ and at $500 \mathrm{ppm}$ concentration the hatching percentage were $17.6 \%, 51.8 \%$ and $67.6 \%$ after $24 \mathrm{~h}, 48 \mathrm{~h}$ and $72 \mathrm{~h}$, respectively (Table 1 ). One hundred percent hatching was observed in the positive and negative controls. Hatching percentage of eggs was shown up to $10 \mathrm{ppm}$ for both of the species after 24,48 and $72 \mathrm{~h}$ (Table 1). Eggs of $A$. aegypti and C. quinquefasciatus were found to be less susceptible to $L$. alba oil. LC50 value could not be calculated as the hatching percent was higher even at the high dose (Table 1).

\section{Larvicidal activity}

During the study of larvicidal activity of the essential oil of $L$. alba, it was found that the larval mortality was directly related to the exposure time and concentration of the oil. Larvae of $C$. quinquefasciatus were found to be more susceptible to $L$. alba oil with LC50 value of $275.66 \mathrm{ppm}$, while in the case of Aedes aegypti it was recorded as $631.29 \mathrm{ppm}$ at $24 \mathrm{~h}$ exposure period (Table 2). No larval mortality was observed in the positive and negative control. The doses of sublethal concentrations are presented along with the regression equations, a 95\% confidence level in Table 2.

\section{Adulticidal activity}

This plant oil was found to cause little effect against adult stages of the two mosquito species even at the

Table 1 Hatching percentage of eggs of two target species after the treatment of Lippia alba oil

\begin{tabular}{|c|c|c|c|c|c|c|c|c|}
\hline \multirow{2}{*}{$\frac{\text { Sl. no }}{1}$} & \multirow{2}{*}{$\frac{\text { No. of individuals }}{50}$} & \multirow[t]{2}{*}{ Concentration (ppm) } & \multicolumn{3}{|c|}{ Aedes aegypti } & \multicolumn{3}{|c|}{ Culex quinquefasciatus } \\
\hline & & & $24 \mathrm{~h}$ & $48 \mathrm{~h}$ & $72 \mathrm{~h}$ & $24 \mathrm{~h}$ & $48 \mathrm{~h}$ & $72 \mathrm{~h}$ \\
\hline & & 1000 & $11.9 \pm 0.89$ & $45.9 \pm 2.44$ & $50.4 \pm 1.14$ & $9.7 \pm 2.11$ & $32.2 \pm 1.55$ & $43.6 \pm 0.59$ \\
\hline & & 500 & $17.6 \pm 0.11$ & $51.8 \pm 0.67$ & $67.6 \pm 0.89$ & $15.4 \pm 0.33$ & $42.3 \pm 1.14$ & $59.9 \pm 1.22$ \\
\hline & & 250 & $21.7 \pm 0.33$ & $67.1 \pm 0.89$ & $75.2 \pm 1.14$ & $18.3 \pm 1.55$ & $48.4 \pm 0.59$ & $62.5 \pm 2.11$ \\
\hline & & 100 & $54.1 \pm 0.67$ & $69.5 \pm 1.55$ & $81.4 \pm 0.67$ & $41.5 \pm 0.89$ & $56.3 \pm 1.55$ & $72.1 \pm 0.33$ \\
\hline & & 50 & $84.3 \pm 2.44$ & $100 \pm 0$ & $100 \pm 0$ & $65.3 \pm 2.11$ & $76.1 \pm 0.11$ & $86.5 \pm 0.89$ \\
\hline & & 10 & $100 \pm 0$ & $100 \pm 0$ & $100 \pm 0$ & $100 \pm 0$ & $100 \pm 0$ & $100 \pm 0$ \\
\hline
\end{tabular}


Table 2 LC50 concentration (ppm) of Lippia alba oil against larval stages of Aedes aegypti and Culex quinquefasciatus

\begin{tabular}{|c|c|c|c|c|c|c|c|c|c|c|}
\hline \multirow[t]{3}{*}{ Time } & \multicolumn{5}{|c|}{ Aedes aegypti } & \multicolumn{5}{|c|}{ Culex quinquefasciatus } \\
\hline & \multirow{2}{*}{$\begin{array}{l}\text { LC50 } \\
\text { (ppm) }\end{array}$} & \multirow{2}{*}{$\begin{array}{l}\text { Regression } \\
\text { equation }\end{array}$} & \multicolumn{2}{|c|}{ 95\% confidence level } & \multirow{2}{*}{$\begin{array}{l}\text { Chi- } \\
\text { square } \\
\text { value }\end{array}$} & \multirow{2}{*}{$\begin{array}{l}\text { LC50 } \\
(\mathrm{ppm})\end{array}$} & \multirow{2}{*}{$\begin{array}{l}\text { Regression } \\
\text { equation }\end{array}$} & \multicolumn{2}{|c|}{ 95\% confidence level } & \multirow{2}{*}{$\begin{array}{l}\text { Chi- } \\
\text { square } \\
\text { value }\end{array}$} \\
\hline & & & Lower bound & Upper bound & & & & Lower bound & Upper bound & \\
\hline $24 \mathrm{~h}$ & 631.29 & $Y=-1.83+2.43 X$ & 2.261 & 3.462 & 50.960 & 275.66 & $Y=.12+1.99 X$ & 1.645 & 2.344 & 21.493 \\
\hline $48 \mathrm{~h}$ & 602.17 & $Y=-1.56+2.36 X$ & 2.041 & 3.105 & 61.253 & 208.74 & $Y=1.31+1.58 X$ & 1.300 & 1.863 & 28.722 \\
\hline $72 \mathrm{~h}$ & 552.82 & $Y=-1.31+2.30 X$ & 1.845 & 2.780 & 51.460 & 155.00 & $Y=1.24+1.71 X$ & 1.434 & 1.996 & 21.622 \\
\hline
\end{tabular}

higher dose of 500 and $1000 \mathrm{ppm}$ concentrations. But after $72 \mathrm{~h}$ of treatment, the survivability percentages of adults were decreased from 60 to $80 \%$ and $50 \%$ to $60 \%$ (Table 3) in the case of $A$. aegypti and C. quinquefasciatus respectively. $100 \%$ survivability was recorded in both positive and negative control. The survivability percentage of adults after $24 \mathrm{~h}, 48 \mathrm{~h}$ and $72 \mathrm{~h}$ of treatment is presented in Table 3. LC50 value could not be calculated as no mortality was observed in the maximum number of concentrations which is shown in Table 3 .

\section{Repellency}

RT50 (repellent time) values were calculated for a constant dose of $1 \mathrm{mg} / \mathrm{cm}^{2}$ for each of the mosquito species at which time 50\% repellency was attained. The lowest RT50 value was observed against C. quinquefasciatus (Table 4).

\section{GC-MS analysis}

To identify different constituent compounds, GC-MS analysis was carried out after extraction of the essential oils from the fresh leaves of $L$. alba. The identity, retention time, area and percentage composition of the major compounds present in the oil of $L$. alba are presented in Table 5. The MS spectra of the major constituents were presented in the Fig. 1. The result showed 2, 7 octadione-1-butoxy, 2-isopropenyl-5-methyl hex-4-enol, aromadendrene oxide and caryophyllene oxide as major probable constituent compounds of the essential oil comprising $11.09 \%, 11.30 \%, 9.96 \%$ and $9.56 \%$ area percentage respectively.

\section{Discussion}

The study regarding the efficacy of the essential oil of $L$. alba for the control of mosquito may eventually lead to their use in natural product-based mosquito subsiding practices. In the current investigation, the essential oil of L. alba was employed against different developmental stages of C. quinquefasciatus and A. aegypti, and it was found that the same plant oil exhibited different activity showing higher efficacy against $C$. quinquefasciatus than Aedes aegypti. These differences might be due to diverse genetic constituency and differential rate of transcription of various genes responsible for the production of detoxifying enzymes like esterase, mixed-function oxidases and glutathione-S-transferases involved in these two targeted mosquito species (Harker et al. 2013; Sarkar, Bhattacharyya, Borkotoki, Baruah, and Srivastava, 2009).

The developmental stages of $A$. aegypti and C. quinquefasciatus were not equally affected by the same essential oil while offering the same environmental conditions. The eggs were more resistant to the plant product than the larval stages of both the mosquito species as eggs show higher resistance to any physical or chemical stress due to the encapsulation of the chorionic membrane. Again, the larval stages of both the species were found more susceptible compared to other developmental stages which were in conformity to the finding of Fox, Roff, and Fairbairn (2011) where they reported the larval stage as more responsive to any physical and chemical stresses than the other developmental stages. Moreover, in the current study, the larval stages of $C$. quinquefasciatus were found more vulnerable towards insecticides than that of $A$. aegypti (Table 2) which is

Table 3 Survivability percentage of adult C. quinquefasciatus and A. aegypti after the treatment of L. alba oil

\begin{tabular}{|c|c|c|c|c|c|c|c|c|}
\hline \multirow{2}{*}{$\frac{\text { Serial No }}{1}$} & \multirow{2}{*}{$\frac{\text { No of individuals/replica }}{10}$} & \multirow{2}{*}{$\begin{array}{l}\text { Concentration (ppm) } \\
1000\end{array}$} & \multicolumn{3}{|c|}{ Aedes aegypti } & \multicolumn{3}{|c|}{ Culex quinquefasciatus } \\
\hline & & & $24 \mathrm{~h}$ & $48 \mathrm{~h}$ & $72 \mathrm{~h}$ & $24 \mathrm{~h}$ & $48 \mathrm{~h}$ & $72 \mathrm{~h}$ \\
\hline & & & $100 \pm 0$ & $100 \pm 0$ & $60 \pm 0.89$ & $100 \pm 0$ & $100 \pm 0$ & $50 \pm 0.33$ \\
\hline & & 500 & $100 \pm 0$ & $100 \pm 0$ & $80 \pm 0.33$ & $100 \pm 0$ & $100 \pm 0$ & $60 \pm 0.33$ \\
\hline & & 250 & $100 \pm 0$ & $100 \pm 0$ & $100 \pm 0$ & $100 \pm 0$ & $100 \pm 0$ & $100 \pm 0$ \\
\hline & & 100 & $100 \pm 0$ & $100 \pm 0$ & $100 \pm 0$ & $100 \pm 0$ & $100 \pm 0$ & $100 \pm 0$ \\
\hline & & 50 & $100 \pm 0$ & $100 \pm 0$ & $100 \pm 0$ & $100 \pm 0$ & $100 \pm 0$ & $100 \pm 0$ \\
\hline & & 10 & $100 \pm 0$ & $100 \pm 0$ & $100 \pm 0$ & $100 \pm 0$ & $100 \pm 0$ & $100 \pm 0$ \\
\hline
\end{tabular}


Table 4 RT50 values of L. alba oil against A. aegypti and C. quinquefasciatus

\begin{tabular}{|c|c|c|c|c|c|c|c|c|c|c|}
\hline \multirow[t]{3}{*}{ Time } & \multicolumn{5}{|c|}{ Aedes aegypti } & \multicolumn{5}{|c|}{ Culex quinquefasciatus } \\
\hline & \multirow{2}{*}{$\begin{array}{l}\text { RT50 } \\
\text { (min) }\end{array}$} & \multirow{2}{*}{$\begin{array}{l}\text { Regression } \\
\text { equation }\end{array}$} & \multicolumn{2}{|c|}{ 95\%confidence level } & \multirow{2}{*}{$\begin{array}{l}\text { Chi- } \\
\text { square } \\
\text { value }\end{array}$} & \multirow{2}{*}{$\begin{array}{l}\text { RT50 } \\
\text { (min) }\end{array}$} & \multirow{2}{*}{$\begin{array}{l}\text { Regression } \\
\text { equation }\end{array}$} & \multicolumn{2}{|c|}{ 95\% confidence level } & \multirow{2}{*}{$\begin{array}{l}\text { Chi- } \\
\text { square } \\
\text { value }\end{array}$} \\
\hline & & & Lower bound & Upper bound & & & & Lower bound & Upper bound & \\
\hline 1 & 110.42 & $Y=8.49-1.711 x$ & 3.346 & 3.661 & 19.955 & 86.6 & $Y=11.03-3.12 x$ & 5.715 & 6.136 & 62.091 \\
\hline
\end{tabular}

similar to the findings of Shaalan, Canyon, Younes, Wahab, and Monsour (2005). The presence of caryophyllene oxide, armodendrene oxide in the constituent profile of $L$. alba oil might be the possible reason for the larvicidal activity Mathew and Thoppil (2011).

In our study, the adulticidal activity of $L$. alba oil was found to be very low even at higher doses (Table 3). Lower adulticidal toxicity of Lippia oil was also previously reported in the case of $L$. polystachyaty and $L$. turbinate Gleiser and Zygadlo (2007). Since the possibility of contact toxicity and the toxicity through ingestion is lesser in the case of adult individuals, the possible way of most of the terpene compounds to enter the adult insect's body is through the respiratory system (fumigant toxicity), Gnankine and Bassole, 2017. This might be a reason for the lower adulticidal activity of the oil found against selected mosquito species. Besides this, the behavioural activity of adults may also result in the lower activity of essential oil of $L$. alba.

The testing of the potentiality of the essential oil as repellent is highly valuable for making safe protection from the bite of various blood-sucking mosquitoes. Repellent properties of essential oils appear to be related to the presence of monoterpenoids and sesquiterpenes. The sesquiterpene compound caryophyllene oxide, which was one of the major constituent compounds of $L$. alba oil had earlier showed a strong repellent effect against different agricultural pests (Kim et al. 2010). The high volatility of caryophyllene oxide likely entered the targeted insect by vapour action via the respiratory system, but further work is needed to confirm their exact mode of action. In the present observation, Lippia oil has showed the potential results as a repellent against both of the target species and in the case of $C$. quinquefasciatus, its RT50 value was lower than that of $A$. aegypti (Table 4). The age, body size, etc. are also responsible for such differences in their response to the same essential oil. Barnard, Posey, Smith, and Schreck, 1998.
The important contributors for larvicidal and repellent properties of the essential oil of $L$. alba might be the major compounds present in the essential oil Gleiser and Zygadlo, 2007 though interactions of other minor compounds also assist for the same. The result of GCMS analysis revealed the presence of 2, 7 octadione-1butoxy, 2- isopropenyl-5-methyl hex-4-enol, aromadendrene oxide and caryophyllene oxide as major compounds (Table 5). But the previous reports of GC-MS analysis had implied the presence of citral, carvone, limonene as the major compounds in the essential oil of $L$. alba (da Silva et al. 2018). This variation in the composition might be depended on topographical as well as climatic condition Ngassapa et al. (2003) of the place where the plant grows. Some of the major constituent compounds of $L$. alba oil viz. caryophyllene oxide, 2isopropenyl-5-methyl hex-4-enol, etc. were earlier reported to present in essential oils of some other plants having high insecticidal properties like oil of Piper nigrum (Mohammed and Omran, A.M. and Hussein, H.M., 2016; Yang, Ma, and Zheng, 2005).

Generally, the biological activity of natural products is related to the nature and position of the functional groups and molecular configuration (Sarma, Adhikari, Mahanta, and Khanikor, 2019). Among the four major constituents mentioned above (Table 5), oxygenated monoterpenes, namely, 2-isopropenyl-5-methyl hex-4enol may also involve in the insecticidal and repellent activity of $L$. alba oil as because it has already been reported that oxygenated monoterpenoids are more toxic than non-oxygenated monoterpenoids (Bozovic, Pirolli, and Ragno, 2005).

\section{Conclusion}

Thus, in brief, the essential oil extracted from the leaves of $L$. alba could be promoted as an efficient repellent and larvicidal agent, which is more effective against $C$.

Table 5 Probable major components of essential oil of L. alba

\begin{tabular}{llllll}
\hline Component & Molecular weight & Retention index & Chemical formula & Area (percent) & Retention time (min) \\
\hline Caryophyllene oxide & 220 & 1576 & $\mathrm{C}_{15} \mathrm{H}_{24} \mathrm{O}$ & 9.56 & 12.61 \\
2, 7 octadione-1-butoxy & 182 & 1288 & $\mathrm{C}_{12} \mathrm{H}_{22} \mathrm{O}$ & 11.09 & 4.07 \\
2- isopropenyl-5-methyl hex-4-enol & 152 & 1092 & $\mathrm{C}_{10} \mathrm{H}_{16} \mathrm{O}$ & 11.30 & 7.86 \\
Aromdendrene oxide & 220 & 1678 & $\mathrm{C}_{15} \mathrm{H}_{24} \mathrm{O}$ & 9.96 & 13.44 \\
\hline
\end{tabular}


quinquefasciatus than $A$. aegypti. As natural products are favoured in vector control measures due to their less deleterious effect, such kind of studies could encourage a researcher to explore new alternatives to synthetic repellents and insecticides.

\section{Abbreviations}

Dept: Department; DMSO: Dimethylsulfoxide; GC MS: Gas chromatography mass spectrometry; IIT: Indian Institute of Technology; LC: Lethal concentration; No: Number; PPM: Parts per million; RMRC: Regional Medical Research Centre; RT: Repellent time; SAIF: Sophisticated Analytical Instrumentation Facility; SPSS: Statistical Package for the Social Sciences; Ta: Total number of mosquitoes in the control group; Tb: Total number of mosquitoes in the treated group

\section{Acknowledgements}

The authors are very much thankful to Dr. D. R. Bhattacharyya, RMRC, Dibrugarh, Assam, India and Dr. Gajen Sarma, Department of Botany, Gauhati University, Assam, India, for helping in the identification of the mosquito species and the plant species respectively. We are also grateful to the Sophisticated Analytical Instrumentation Facility (SAIF), IIT Bombay, for their valuable assistance.

\section{Authors' contributions}

SM performed the bioassay, analysed and interpreted the data. RS collected the plant material. BK was a major contributor in writing the manuscript. All authors read and approved the final manuscript.

\section{Funding}

We are thankful to the University Grant Commission (via grant number Z BSR/2015-16/71), for their financial support.

\section{Availability of data and materials}

The datasets used and/or analysed during the current study are available from the corresponding author on reasonable request.

\section{Ethics approval and consent to participate}

We have got permission from the Institutional Animal Ethical Committee, Gauhati University via Reference number IAEC/Per/2019/RF/2019-021 for using mosquitoes as experimental animals and human participants for the repellency test.

\section{Consent for publication}

Not applicable

\section{Competing interests}

The authors declare that they have no competing interests.

Received: 10 July 2019 Accepted: 9 October 2019

Published online: 11 December 2019

\section{References}

Arivoli, S., \& Tennyson, S. (2011). Larvicidal and adult emergence inhibition activity of Abutilon indicum (Linn.) (Malvaceae) leaf extracts against vector mosquitoes (Diptera: Culicidae). Journal of Biopesticides, 4(1), 27-35.

Barnard, D., Posey, K. H., Smith, D., \& Schreck, C. E. (1998). Mosquito density, biting rate and cage size effects on repellent tests. Medical and Veterinary Entomology, 12, 39-45.

Bozovic, M., Pirolli, A., \& Ragno, R. (2005). Mentha suaveolens (Lamiaceae) essential oil and its main constituent piperitenone oxide: biological activities. Molecules, 20, 8605-8633.

Castillo, R. M., Stashenko, E., \& Duque, J. E. (2017). Insecticidal and repellent activity of several plant-derived essential oils against Aedes aegypti. Journal of American Mosquito Control Association, 33(1), 25-35.

Da Silva, L. V. F., Moura, R. H. V., Manimala, J., \& Lnenicka, G. A. (2018). The essential oil of Lippia alba and its components affect Drosophilabehavior and synaptic physiology. Journal of Experimental Biology, 221, 1-10.

Fox, C. W., Roff, D. A., \& Fairbairn, D. J. (2011). Evolutionary ecology: concepts and case studies. UK: Oxford University Press.
Gleiser, R. M., \& Zygadlo, J. A. (2007). Insecticidal properties of essential oils from Lippiaturbinata and Lippiapolystachya (Verbenaceae) against Culex quinquefasciatus (Diptera: Culicidae). Parasitology Research, 101, 1349-1354.

Gnankine, O., \& Bassole, I. H. N. (2017). Essential oils as an alternative to pyrethroids resistance against Anopheles species complex giles (Diptera: Culicidae). Molecules, 22, 1321

Harker, B. W., Behura, S. K., Bruyn, B. S., Lovin, D. D., Mori, A., Romero-Severson, J., \& Severson, D. W. (2013). Stage-specific transcription during development of Aedes aegypti. BMC Developmental Biology, 13, 29

Kim, S. I., Yoon, J. S., Jung, J. W., Hong, K. B., Ahn, Y. J., \& Kwon, H. W. (2010). Toxicity and repellency of origanum essential oil and its components against Triboliumcastaneum (Coleoptera: Tenebrionidae) adults. Journal of Asia Pacific Entomology, 13, 369-373.

Kumar, R., Kumar, A., Prasal, S., Dubey, N. K., \& Samant, R. (2008). Insecticidal activity Aegle marmelos( L.) Correa essential oil against four stored grain insect pests. Internet Journal of Food Safety, 10, 39-49.

Mathew, J., \& Thoppil, J. E. (2011). Chemical composition and mosquito larvicidal activities of Salvia essential oils. Pharmaceutical Biology, 49(5), 456-463.

Mohammed, G. J., Omran, A. M., \& Hussein, H. M. (2016). Antimicrobial and phytochemical analysis of Piper nigrum using gas chromatography mass spectrum and fourier-transform infrared spectroscopy. International Journal of Pharmacognsy and Phytochemical Research, 8(6), 977-996.

Nassar, M. I., Hamed, A. G., Asma, A.-W., Jazem, A. M., \& Khatir, M. A. (2017). Assessment of some chemical and biorational insecticides against Culex Pipiens (Diptera: Culicidae) in Abha City, Saudi Arabia. Journal of the Egyptian Society of Parasitology, 47(3), 617-622.

Ngassapa, O., Runtoro, D. K. B., Harvala, E., \& Chinou, L. B. (2003). Composition and an antimicrobial activity of essential oils of two populations of Tanzanian Lippiajavanical Burm.f.) Spreng.(Verbenaceae). Flavour and Fragrance Journal, 18, 221-224.

Peixoto, M. G., Bacci, L., Blank, A. F., Araujo, A. P. A., Alves, P. B., Silva, J. H. S. S., ... Arrigoni-Blankv, M. D. F. (2015). Toxicity and repellency of essential oils of Lippia alba chemotypes and their major monoterpenes against stored grain insects. Industrial Crops and Products, 71, 31-36.

Pushpanathan, T., Jebanesan, A., \& Govindarajan, M. (2006). Larvicidal, ovicidal and repellent activities of Cymbopogancitrates Stapf (Graminae) essential oil against the filarial mosquito Culex quinquefasciatus (Say) (Diptera: Culicidae). Tropical Biomedicine, 23(2), 208-212

Pushpanathan, T., Jebanesan, A., \& Govindaranjan, M. (2008). The essential oil of Zingiber officinalis Linn (Zingiberaceae) as a mosquito larvicidal and repellent agent against the filarial vector Culex quinquefasciatus Say (Diptera: Culicidae). Parasitology Research, 102, 1289-1291.

Rahmatillah, M., Jahan, R., Azam, F. M. S., Hossan, S., Mollik, M. A. H., \& Rahman, T. (2011). Folk medicinal uses of verbenaceae family plants in Bangladesh. African Journal of Traditional Complementary and Alternative Medicines, 8(S), 53-65.

Ramar, M., Ignacimuthu, S., \& Paulraj, G. M. (2013). Biological activity of nine plant essential oils on the filarial vector mosquito, Culex quinquefasciatus Say (insect: Diptera: Culicidae). International Journal of Research in Biological Science, 1, 1-5.

Sarkar, M., Bhattacharyya, S. I. K., Borkotoki, A., Baruah, I., \& Srivastava, R. B. (2009). Development of physiological resistance and its stage specificity in Culex quinquefasciatus after selection with deltamethrin in Assam, India. Memorias do Instituto Oswaldo Cruz, 104(5), 673-677.

Sarma, R., Adhikari, K., Mahanta, S., \& Khanikor, B. (2019). Combinations of plant essential oil based terpene compounds as larvicidal and adulticidal agent against Aedes aegypti (Diptera: Culicidae). Scientific Reports, 9, 9471.

Shaalan, E. A. S., Canyon, D. V., Younes, M. W. F., Wahab, H. A., \& Monsour, A. H. (2005). Synergistic efficacy of botanical blends with and without synthetic insecticides against Aedes aegypti and Culex annulirostris. Journal of Vector Ecology, 30(2), 284-288.

Tennyson, S., Ravindran, K. J., \& Arivoli, S. (2011). Screening of plant extracts for ovicidal activity against Culex quinquefasciatus, Say( Diptera: Culicidae). Applied Botany, 2040, 5456-5460.

Tong, F., \& Bloomquist, J. R. (2013). Plant essential oils affect the toxicities of carbaryl and permethrin against Aedes aegypti (Diptera: Culicidae). Journal of Medical Entomology, 50(4), 826-832.

Yang, P., Ma, Y., \& Zheng, S. (2005). Adulticidal activity of five essential oils against Culex pipiensquinquefasciatus. Journal of Pesticide Science, 30(2), 84-89.

\section{Publisher's Note}

Springer Nature remains neutral with regard to jurisdictional claims in published maps and institutional affiliations. 